\title{
Waste to energy as a contribution to ravage elimination
}

\author{
P. Stehlík \& M. Pavlas \\ Institute of Process and Environmental Engineering, \\ Brno University of Technology, UPEI - VUT, Brno, Czech Republic
}

\begin{abstract}
The fact that mankind has been facing serious environmental and global problems during recent years is generally known and it is not necessary to emphasize it. However, every concrete way providing us with a method leading to elimination of the ravage of the planet represents a valuable contribution. This paper is aimed at renewable energy in terms of utilizing waste as alternative fuel. The benefit is quite obvious - waste is disposed and its energy content utilized. This approach is called waste to energy

Currently, an increasing amount of waste produced (both municipal solid waste - MSW and industrial and/or hazardous waste - IHW) can be considered as a driving force for finding efficient ways for the thermal processing when waste is removed and at the same time used as a valuable fuel. It represents a challenge for potential investors and operators as well as researchers.

It is necessary to take into account the following needs:

- waste disposal as a necessity

- waste-to-energy as the main aim

- limitations given by environmental legislation

- locality - big cities or villages
\end{abstract}

An idea about building new regional Waste-to-Energy Centers (WTEC) is outlined. It is based on a convenient combination of experience, know-how and sophisticated approach. WTEC is equipped with:

- a unit for the thermal treatment of hazardous industrial wastes

- a unit for the thermal treatment of common MSW

- a special incinerator for the thermal treatment of sewage sludge if more waste water treatment plants are situated in the region

- a system for sorting and separation of wastes connected with a production of alternative fuels

- a system for utilizing ash and flying ash for secondary building materials

WTEC has to be based on up to date technology which enables a further extension and innovation initiated usually by increasing population and standard of living as well as more and more sweeping environmental limits.

Keywords: waste, energy, sustainable development, emissions reduction. 


\section{Introduction}

Serious problems are currently solved in the field of environmental protection. The challenge facing concerned citizens and decision-makers is a formidable one: To identify and implement long-term solutions that are safe, socially acceptable, and cost-effective. Such amounts of waste, which are produced either by inhabitants (municipal solid waste - MSW, see Figure 1, [1]) or by industrial companies (industrial and hazardous waste - IHW) require one to use efficient ways of waste disposal. The recent focus on incineration has been on environmental consequences, not on performance.

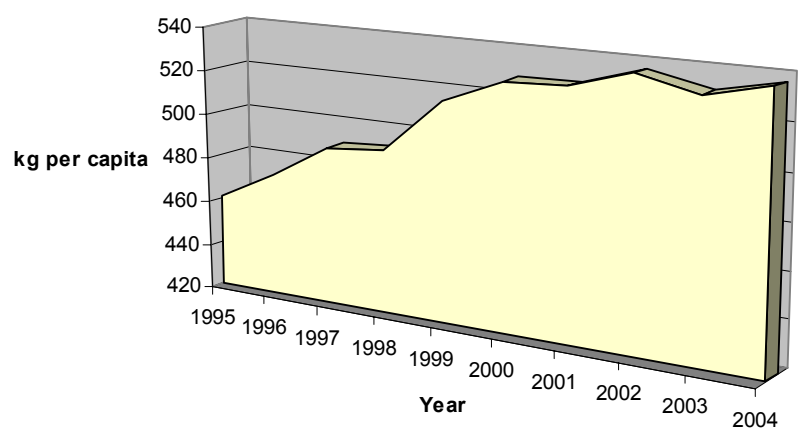

Figure 1: Municipal waste collected per capita (kg per capita) in the European union [1].

One of other global problems of the human race is the greenhouse effect. Principles and methods of reaching the given targets in this field are well known and do not need further attention:

- reducing process energy consumption

- increasing the effectiveness of energy utilization stored in fossil fuels

- $\quad$ strong use of renewable energy sources.

The preferred sources of renewable energy are, apart from biomass, also thermal treatment of waste with heat recovery. It can be said, that waste stops to be a problem and becomes an available fuel, which brings two advantages waste is treated and at the same time energy is produced. Then we speak about waste-to-energy technology (WTE). WTE is also referred to as thermal processing of wastes including energy utilization [2-4].

\section{Primary Energy Saving by WTE}

Due to the more and more sweeping environmental limits on the quality of side products of waste combustion (flue gas, solid residues and waste water) WTE systems can provide us with clean and reliable energy in the form of heat as well as power $\left(Q_{\text {exp }}\right.$, Figure 2). In a number of countries energy from WTE systems is considered to be renewable energy. 


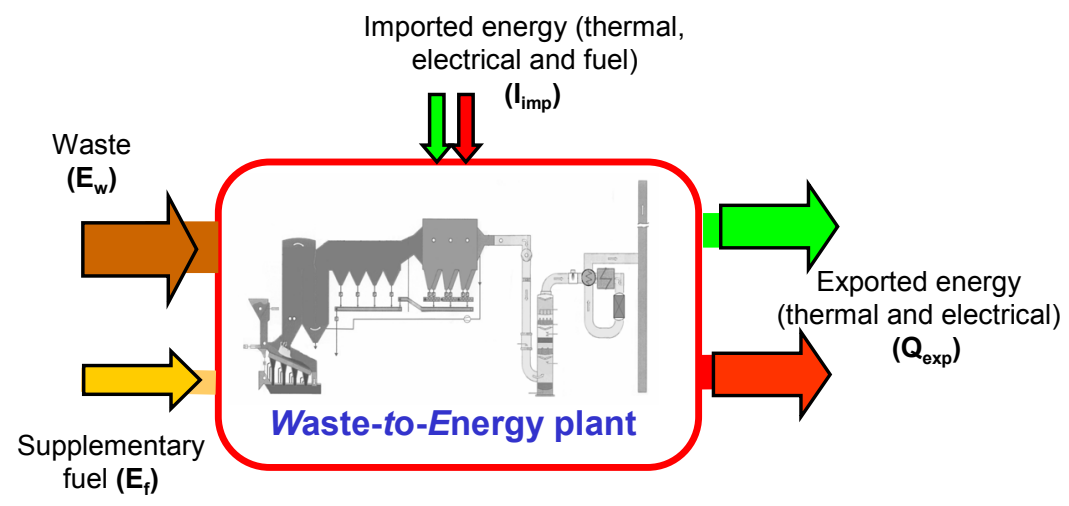

Figure 2: Thermal treatment of waste as a process.

The controlled combustion process is not energy self-sufficient, i.e. it cannot be processed without the consumption of supplementary energy $\left(\mathrm{E}_{\mathrm{f}}, \mathrm{I}_{\mathrm{imp}}\right)$. The consumption $\left(\mathrm{E}_{\mathrm{f}}, \mathrm{I}_{\mathrm{imp}}\right)$ depends on the type of waste incinerated, its calorific content and the thermal regime used. For example for incineration plants it is typical that the lower heating value of waste is sufficient to meet operational requirements without the need of supply of auxiliary energy to the combustion chamber (e.g. combustion of natural gas). On the other hand for IHW incinerators and units, which are not optimized or are not operated efficiently, the specific consumption of energy can be much higher, thus bringing negative economic and environmental effects.

\subsection{Criteria for evaluation}

To compare the effectiveness of energy production in different incineration plants several criteria have been developed by several organizations $[5,6]$. As an example the criterion called Plant Efficiency defined in the BREF [6] can be used. It defines the ratio between energy exported by incinerating the waste and energy consumed by the process itself.

\subsection{WTE and cogeneration}

Thermal treatment of waste is accompanied by the release of a considerable amount of heat, which has to be, if we talk about modern WTE systems, efficiently utilized. The most frequent method of utilizing heat content of flue gas is production of steam in waste heat boiler (heat recovery steam generator, HRSG). The produced steam can be directly consumed on-site but a much more efficient way of utilizing it is production of power and subsequent utilization of the remaining energy for heat supply. In that case a WTE system is also a cogeneration plant (see Figure 2). 


\section{Factors influencing technology selection and plant performance}

For a selection of waste processing technology various criteria have to be respected. First, in most cases it is necessary to "hand-tailor" the technology from case to case. For a customer there is usually a choice of best available technologies (BAT, [6]). However, only few of them (sometimes none of them) are applicable for the given purpose. Then a creativity and all-round potential of the technology supplier (to be selected) plays a key role. There is not a general prescript/instruction how to proceed, however, some general and specific criteria have to be taken into account. It is necessary to always bear in mind the main aim of the incinerator, which is a safe and environmentally friendly disposal of a given amount of waste. At the same time suppliers of 21 st century's incinerators have to respect maximum utilization of energy from the waste incineration

An optimum choice of a waste processing technology is subjected not only economic requirements but especially it is limited by environmental constraints. Then it is necessary to combine all the following factors and make an acceptable trade-off:

- Waste disposal as a necessity

- Waste-to-energy as the main aim

- Limitations given by environmental legislation

- Locality - big cities or villages.

Before looking at the specific factors in more detail it is important to mention a typical unit for municipal solid waste (MSW) incineration (Figure 3, Figure 4). Waste incineration is performed in a combustion chamber equipped by a moving grate under temperatures ranging between 850 and $1000^{\circ} \mathrm{C}$. The heat released in this process is utilised in a heat recovery steam generator (HRSG), where it is cooled down to approximately 250 to $280^{\circ} \mathrm{C}$. Mechanical cleaning of the flue gas is performed in electrostatic precipitator (ESP). Then it enters the block of off-gas cleaning, comprising a dioxin filter (DEDIOX) and a wet scrubber.

\subsection{Waste disposal as a necessity}

To successfully solve a waste treatment process we have to be familiar with the waste character, composition, state (whether solid, liquid, gas and/or a mixture) etc. It is necessary to emphasize important influence of the thermal regime in the combustion chamber on the auxiliary energy consumption [7]. It is based mainly on the consumption of supplementary fuel used to achieve and maintain the conditions for complete oxidation of all combustibles (with an emphasis on the so-called "3T" Time, Temperature, Turbulence). It is generally known that the minimal temperature of gaseous products after the last air input is given by legislation and it differs according to the type of processed waste [8].

A typical example of waste with a very low heating value, the combustion of which is linked with a higher consumption of supplementary fuel, is sludge from 


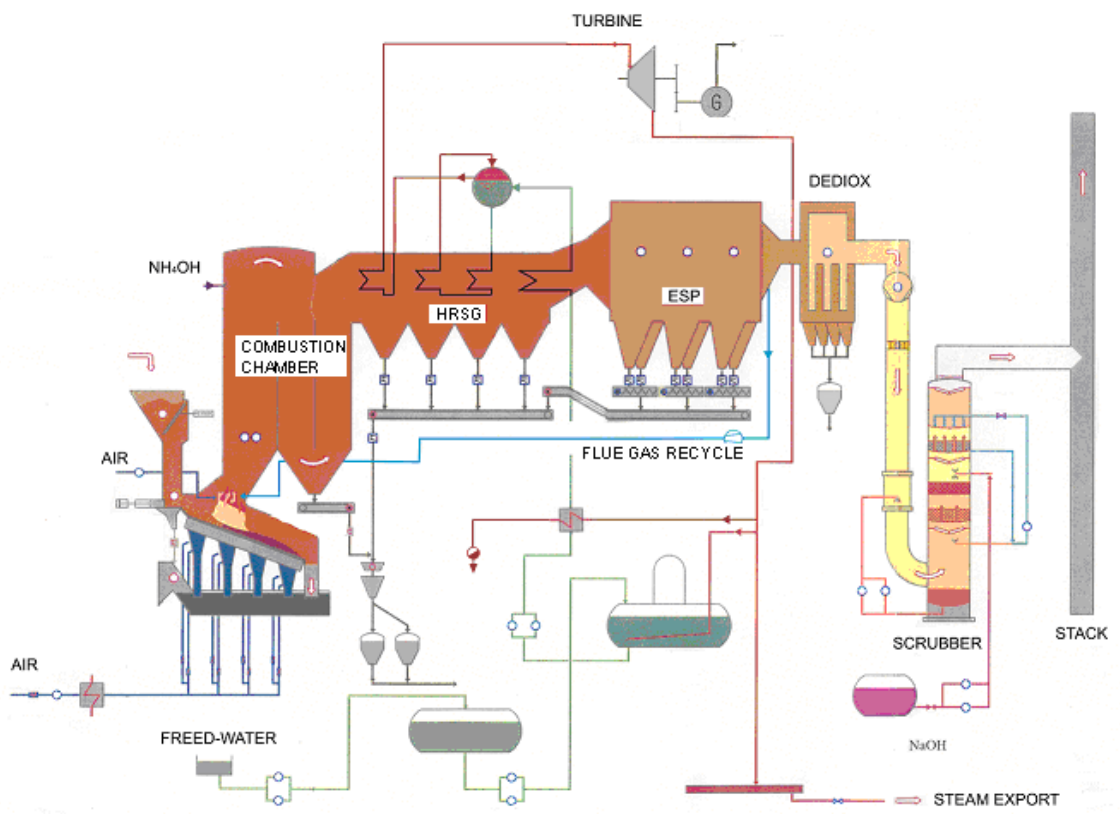

Figure 3: Typical configuration of up-to-date municipal solid waste incinerator (courtesy of TERMIZO Liberec Ltd.).

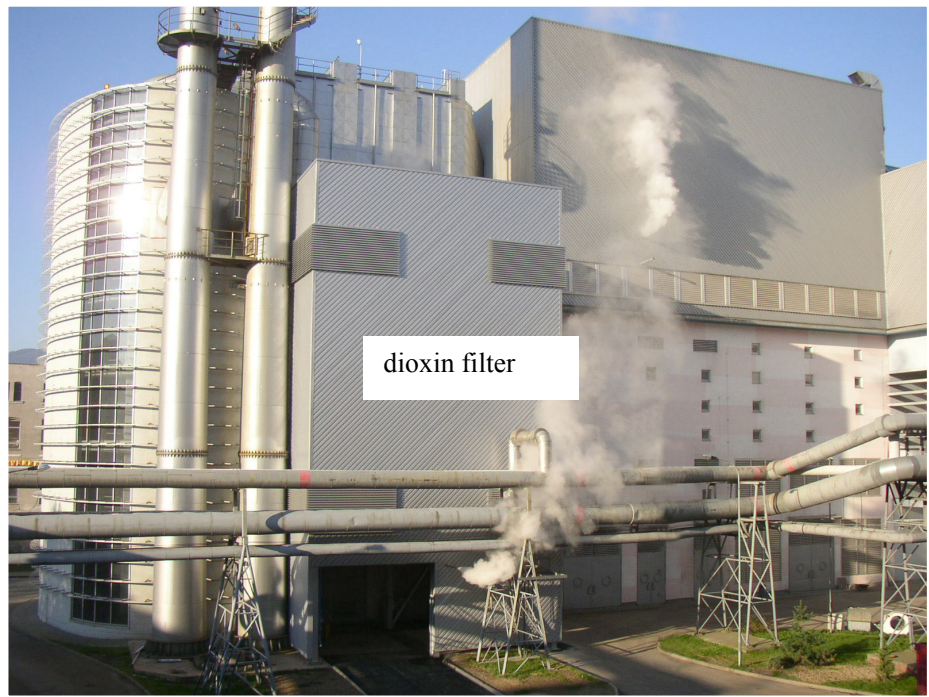

Figure 4: Up-to-date MSW incinerator with capacity of $300 \mathrm{t} /$ day and new dioxin filter (courtesy of EVECO Brno Ltd.). 
industrial processes and wastewater treatment plants. Processing of this type of waste requires specific technologies that are "hand-tailored" from case to case $[9,10]$. The following example shows thermal treatment of industrial sludge in unit with a multiple hearth combustion chamber with fluidized bed (see Figure 5:). An interesting feature of this system consists in substituting natural gas by mining gas (from closed coal mines), which means using alternative fuel. It required development of a specific original burner [11].

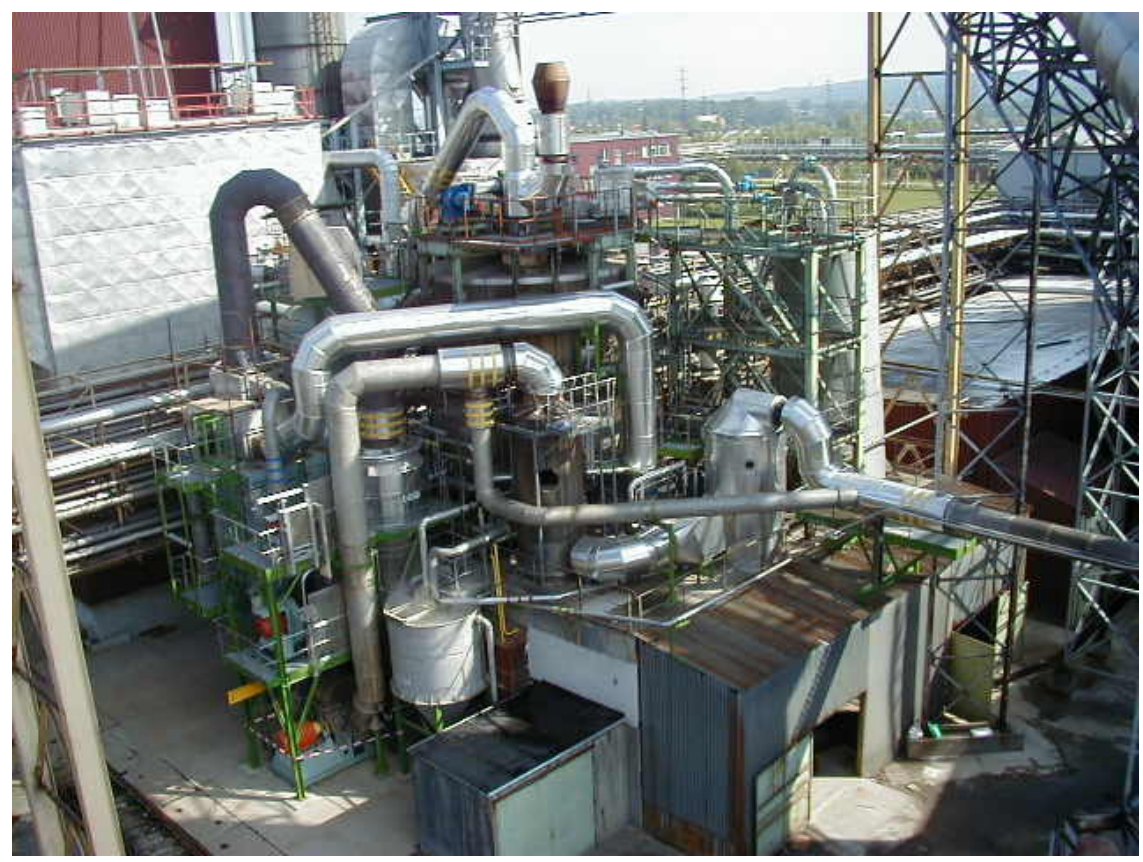

Figure 5: Unit for thermal treatment of sludge from pulp production (courtesy of EVECO Brno Ltd).

\subsection{Waste-to-energy as the main aim}

Heat recovery in units for the thermal processing of various types of wastes can be without any doubts considered as one of the most important parts of these processes. Design of equipment for utilization of energy contained in the flue gas and their placement in the process is one of key factors in these technologies. At the same time it is necessary to tackle the question of integration of a WTE system, in the sense of finding a suitable consumer of heat released by the combustion process. The main result of an analysis of the heat recovery system lay-out and influence of the main parameters were presented in [12].

The highest efficiency expressed in saving of primary energy sources is reached when backpressure turbine is applied. In this case all the steam going through the turbine and used for power generation is then utilised for heating purposes, which results in higher efficiency. However the disadvantage of this 
system is the direct dependence of the incinerator on the grid conditions, to which steam is distributed. Suitable consumers of heat for this application are for example industrial processes with steady heat consumption. On the other hand these processes usually require higher parameters of steam to supply heat to the cold process streams. Of course this has a negative effect on plant performance, since less power is produced, which is considered to be a more valuable type of energy than heat, as a result of reduction of the heat drop over the turbine.

On the other hand steam with relatively low parameters can be effectively utilized for hot water production in systems of district heating in the field of municipal energy supply. In that case it is necessary ensure that the incinerator heat output can be utilized all year round. This could be quit serious problem, if WTE system is integrated into a relatively small district heating system in an area with a mild climate, where the heat consumption in summer months is very low. A very flexible solution for such unsteady heat consumption is application o bleeding condensing turbine, where excess steam is utilized for power production. However the consequences of so-called summer operation mode with a reduced heat output and increased power output on plant performance is evident - the efficiency of the cycle as well as primary energy saving are considerably lower.

\subsection{Limitations given by environmental legislation}

The system of flue gas cleaning is another important part of units for thermal processing of waste. Off gases polluted by $\mathrm{NO}_{x}, \mathrm{SO}_{2}, \mathrm{HCl}, \mathrm{HF}$, fly ash and dioxins and furans (PCDD/F) flow through a number of equipment with the aim of reducing the concentration of harmful compounds to the level below emission limits. In connection with more and more sweeping emission limits, the requirements on each equipment unit, which the off-gas cleaning system consist of, are increasing. At the same time, its integration into the technology is just as important.

As an example of possible technology extension in the future it can be shown that a baghouse filter with a special material for removal not only solid particles but also PCDD/F (dioxins) will be necessary in the nearest future and MSW incinerators have to be adapted accordingly to enable an easy way of potential retrofit. Dioxins (collective name for polychlorinated - dibenzo-pdioxins and dibenzofurans) belong among the most dangerous pollutants, elimination of which from the products of incineration (solid residues, flue gas) is a necessity strictly required by legislation. For example in the EU, the present limit on dioxin emissions is $0.1 \mathrm{TEQng} / \mathrm{m}_{\mathrm{N}}{ }^{3}$ (whereas e.g. in China the current limit is $1 \mathrm{TEQ} n g / \mathrm{m}_{\mathrm{N}}^{3}$ ). It is therefore very attractive to employ technologies that actually destroy dioxins instead of only collecting them. The latest achievement in this respect is the catalytic filtration technology REMEDIA $^{\mathrm{TM}}$ of the company W.L. Gore \& Associates Inc., which combines fabric filtration (collection of particulate matter) with catalytic destruction of dioxins. A recent information on the performance of this technology applied in a municipal waste incinerator may be found e.g. in [13]. 


\subsection{Locality}

Last but not least factor, which influence technology selection is the locality. In agglomerations and large cities with high density of population and/or industrial areas there is possible to solve the problem by a standard way, in small towns and villages it is necessary to find a specific way.

\section{Waste to Energy Centre}

Thermal processing of various types of wastes is not only waste disposal and/or treatment at present. It has to be regarded as waste to energy process wherever and whenever possible and feasible. Therefore an idea about founding and building new regional Waste-to-Energy Centers (WTEC) is outlined. It is based on a convenient combination of experience, know-how and sophisticated approach.

The main fact influencing the concept of WTEC is the necessity to treat different types of wastes. Typical types of wastes as well as main products of the processes which proceed in the WTEC are shown in Figure 6.

In case of establishing such a WTEC the following principle advantages are of primary importance:

- substantial contribution to environmental protection

- $\quad$ saving natural raw material and energy resources

- increasing employment

- $\quad$ source of regions' income.

Of course general common principles have to be respected like e.g. the following ones:

- $\quad$ sorting of waste

- waste recycling and utilizing all known processes for the treatment of biodegradable wastes

- $\quad$ permanent developing the environmental legislative framework

- necessity of people's education (in this field) starting from early youth, and under support of media and public administration.

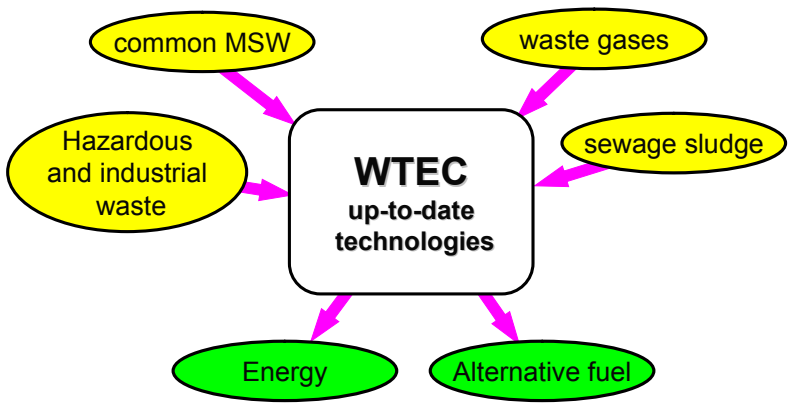

Figure 6: Types of waste processed in WTEC. 
Then it is necessary to evaluate the situation in terms "what is available". WTEC should be equipped by basic items such as:

- unit for the thermal treatment of hazardous industrial wastes

- unit for the thermal treatment of common MSW

- special incinerator for the thermal treatment of sewage sludge if more waste water treatment plants are situated in the region

- system for sorting and separation of wastes connected with a production of alternative fuels

- $\quad$ system for utilizing ash and flying ash for secondary building materials

- $\quad$ cogeneration (Combined Heat and Power System - CHP)

To put it into practice a view from both user and supplier has to be taken into account, i.e. "what do we need" and "what we are able to offer", respectively. Last but not least it is necessary to adapt the WTEC system according to local conditions, region's character, agricultural or industrial area etc.

\section{Conclusions}

Up-to-date incinerator plants cannot be considered only as units for waste disposal, but they have to be looked at as modern energy sources producing renewable energy, The potential for primary energy saving can be seen as the difference in generated and consumed energy. An optimum choice of a waste processing technology is influenced by many factors. Some of them are mentioned in more details in this paper. Last but not least ideas about potential organizing WTEC are outlined provided latest achievements would be utilized.

\section{Acknowledgements}

We gratefully acknowledge financial support of the Ministry of Education, Youth and Sports of the Czech Republic within the framework of research plan No. MSM 0021630502 "Waste and Biomass Utilization focused on Environment Protection and Energy Generation" as well as support from the Czech Science Foundation within project No. 101/05/2469.

\section{References}

[1] Eurostat, Generation and collection of municipal waste, available on http://epp.eurostat.ec.europa.eu, 2006.

[2] Bebar L., Martinak P., Hajek J., Stehlik P., Hajny Z. \& Oral J., Waste to Energy in the Field of Thermal Processing of Waste, Applied Thermal Engineering, 22, pp. 897-906, 2002.

[3] Stehlik P., Progress and Challenges in Thermal Processing of Various Types of Waste, Proc. of the $1^{\text {st }}$ International Conference \& Exhibition on Thermal Treatment and Resource Utilization of Wastes IWTR 2005, Proceedings on CD ROM, Beijing, 2005. (Key-note Lecture.) 
[4] Stasta P., Boran J., Bebar L., Stehlik P. \& Oral J., Thermal Processing of Sewage Sludge, Applied Thermal Engineering, 26, pp. 1420 - 1426, 2006

[5] CEWEP, Discussion paper on criteria for energy recovery in waste incineration plants, Brussels, available on http://www.cewep.com/energy/energy recovery, 2005.

[6] European IPPC Bureau: Reference Document on the Best Available Techniques for Waste Incineration, Brussels, available on http://eippcb.jrc.es, 2005.

[7] Pavlas M., Bébar L. \& Stehlík P. Waste-to-energy systems and their benefit. Proc. of the $1^{\text {st }}$ International Conference \& Exhibition on Thermal Treatment and Resource Utilization of Wastes IWTR 2005, Proceedings on CD ROM, Beijing, 2005.

[8] Council Directive 2000/76/EC of the European parliament and of the council of 4 December 2000 on the incineration of waste, Official Journal of the European Communities, 28. December 2000.

[9] Oral J., Stehlik P., Sikula J, Puchyr R., Hajny Z. \& Martinak P., Energy Utilization from Industrial Sludge Processing, Energy, 30, pp. $1343-$ 1352, 2005.

[10] Borán̆ J., Houdková L., Ucekaj V., Št’asta P. \& Stehlík P., The Analysis of Energy Utilization in Processes for Sewage Sludge Treatment, Applied Thermal Engineering, 2005, (accepted for publication).

[11] Boran J., Houdkova L. \& Stehlik P.. Waste as alternative fuel. Proc. of the $1^{\text {st }}$ International Conference \& Exhibition on Thermal Treatment and Resource Utilization of Wastes IWTR 2005, Proceedings on CD ROM, Beijing, 2005.

[12] Pavlas M., Bébar L., Urban L. \& Stehlík P. Analysis of utilizing energy from thermal processing of waste, Proc. of the 9th Conference on Proces Integration, Modelling and Optimisation for Energy Saving and Pollution Reduction PRES 2006, Proceedings on CD ROM, Prague, 2006.

[13] Bebar L., Puchyr R., Pranghofer G., Parizek T., Bernat P. \& Stehlik P., Optimum involvement of dioxin catalytic filter in a MSW incinerator. Proc. of the Filtech 2005, Wiesbaden, 2005. 